\title{
Oxygen titration in hypercapnic COPD exacerbation
}

\author{
Georg-Christian Funk
}

Published online: 26 February 2019

(C) Springer-Verlag GmbH Austria, part of Springer Nature 2019

\section{Dear editors,}

We kindly thank the colleagues from Golnik for their letter [1]. They rightfully point out that there seems to be an over-oxygenation in our study subjects. Although oxygen titration in hypercapnic chronic obstructive pulmonary disease (COPD) exacerbation was not a specific research question of our study [2], we would like to recap our hospitals' common practice of oxygen therapy in hypercapnic COPD exacerbations, which closely follows the COPD gold guidelines. The 2019 COPD gold guidelines state: "Oxygen therapy is a key component of hospital treatment of an exacerbation. Supplemental oxygen should be titrated to improve patient's hypoxemia with a target saturation of $88-92 \%$. Once oxygen is started, blood gases should be checked frequently to ensure satisfactory oxygenation without carbon dioxide retention and/or worsening acidosis" [3]. Following the admission of a hypercapnic COPD patient to the intensive care unit (ICU), we check blood gases approximately every hour until there is clinical improvement and then extend the check-up intervals to 6-hourly. We try to avoid over-oxygenation in patients with severe COPD, since the ability of deoxygenated hemoglobin to bind $\mathrm{CO}_{2}$ is higher than that of oxygenated hemoglobin (via the so-called Haldane effect) and over-oxygenation increases dead space ventilation by inhibiting the protective effects of hypoxic pulmonary vasoconstriction
[4]. Given our study data we would like to stress that the initial blood gas measurements were taken immediately after arrival in the ICU. We acknowledge that there was a certain amount of over-oxygenation in patients arriving directly from the emergency room; however, the authors would like to point out that this amount of over-oxygenation is routinely quickly corrected on the ICU and should not be representative for the subsequent treatment phase.

Conflict of interest G.-C. Funk declares that he has no competing interests.

Publisher's Note Springer Nature remains neutral with regard to jurisdictional claims in published maps and institutional affiliations.

\section{References}

1. Sarc I, Ziherl K, Esquinas AM. How important is oxygen titration in hypercapnic COPD exacerbation? Wien Klin Wochenschr. 2019;131.

2. Fazekas AS, Aboulghaith M, Kriz RC, Urban M, Breyer MK, Breyer-Kohansal R, Burghuber OC, Hartl S, Funk GC. Longterm outcomes after acute hypercapnic COPDexacerbation; First-ever episode of non-invasive ventilation. Wien Klin Wochenschr. 2018;130:561-8. https://doi.org/10. 1007/s00508-018-1364-6.

3. https://goldcopd.org/wp-content/uploads/2018/11/ GOLD-2019-v1.7-FINAL-14Nov2018-WMS.pdf, Page 118. Accessed 24.02.2019.

4. Abdo WF, Heunks LM. Oxygen-induced hypercapnia in COPD: myths and facts. Crit Care. 2012;16(5):323. https:// doi.org/10.1186/cc11475.
Prim. PD Dr. G.-C. Funk ( $\bowtie)$

2 Medizinische Abteilung mit Pneumologie mit

Ambulanz, Pavillon 26, Wilhelminenspital,

Montleartstraße 37, 1160 Wien, Austria

georg-christian.funk@wienkav.at 